International Journal of Electrical and Computer Engineering (IJECE)

Vol. 10, No. 3, June 2020, pp. 2850 2860

ISSN: 2088-8708, DOI: 10.11591/ijece.v10i3.pp2850-2860

\title{
Enhancing radial distribution system performance by optimal placement of DSTATCOM
}

\author{
S. F. Mekhamer', R. H. Shehata ${ }^{2}$, A. Y. Abdelaziz ${ }^{3}$, M. A. Al-Gabalawy ${ }^{4}$ \\ ${ }^{1,3}$ Faculty of Engineering and Technology, Future University in Egypt, Cairo, Egypt \\ ${ }^{2}$ Electrical Power and Machines Department, Faculty of Engineering, Ain Shams University, Cairo, Egypt \\ ${ }^{4}$ Pyramids Higher Insitiute for Engineering and Technology, Cairo, Egypt
}

\begin{tabular}{l}
\hline Article Info \\
\hline Article history: \\
Received Jun 1, 2019 \\
Revised Dec 12, 2019 \\
Accepted Dec 18, 2019 \\
\hline
\end{tabular}

\section{Keywords:}

DSTATCOM placement

Grey wolf optimizer

Power loss minimization

Voltage profile improvement

\begin{abstract}
In this paper, A novel modified optimization method was used to find the optimal location and size for placing distribution Static Compensator in the radial distribution test feeder in order to improve its performance by minimizing the total power losses of the test feeder, enhancing the voltage profile and reducing the costs. The modified grey wolf optimization algorithm is used for the first time to solve this kind of optimization problem. An objective function was developed to study the radial distribution system included total power loss of the system and costs due to power loss in system. The proposed method is applied to two different test distribution feeders ( 33 bus and 69 bus test systems) using different Dstatcom sizes and the acquired results were analyzed and compared to other recent optimization methods applied to the same test feeders to ensure the effectiveness of the used method and its superiority over other recent optimization mehods. The major findings from obtained results that the applied technique found the most minimized total power loss in system, the best improved voltage profile and most reduction in costs due power loss compared to other methods.
\end{abstract}

Copyright () 2020 Institute of Advanced Engineering and Science. All rights reserved.

\section{Corresponding Author:}

R. H. Shehata,

Electrical Power and Machines Department,

Ain Shams University,

Cairo, Egypt.

Email: ramyhassan42@yahoo.com

\section{INTRODUCTION}

The performance of radial distribution feeder (RDS) could be measured by many factors which include but not limited to total active and reactive power losses, system voltage profile, power flow, reactive power installed, voltage stability, cost reduction, power quality and total system operation costs [1-2]. Some devices and Equipment as Distributed Generation units and reactive power compensators are an effective solution to enhance, control and mitigate some of the previously mentioned assessment factors of any tested radial distribution feeder. The Electric Power Research Institute (EPRI) developed flexible AC transmission system (FACTS) controllers in which power flow is enourmosly controlled by utilizing different power electronic devices. FACTS controllers such as static var compensator, unified power flow controller and static synchronous compensator (STATCOM) are a promising and effective alternative to enhance the power transfer capability by $20-30 \%$ and stability of the network by regulating the bus voltages and redistributing the line flows [2-4]. By adjusting and varying the firing angles of the thyristors inside the FACT devices, the reactive power injected or absorbed could be controlled in order to improve the performance and characterisitics of the transmission and distributions systems. The STATCOM is more reliable and faster reacting than the switched capacitor. FACT devices are connected to power system at specified locations either in shunt or series connection or combination of both. Distribution static synchronous compensator 
(DSTATCOM) has many features, such as less harmonic production, low power losses, low cost, high regulatory capability and compact size $[5,6]$.

Naseer M., et al., [7] proposes the use of genetic algorithm to find the appropriate size and location of STATCOM in a power system considering the power factor correction limits. The proposed method is applied to IEEE 5 bus, IEEE 30 bus test systems and Iraqi national grid to show the results. However, the proposed technique needs to be applied to larger test radial systems to ensure its effectiveness. Also, the voltage profile status after placement of the statcom in IEEE 30 bus and Iraqi national grid is not shown. Yuvaraja, et al., [8] discusses the use of harmony search algorithm for the optimal sizing and location of DSTATCOM in RDS. The method is tested only on IEEE 33 bus to ensure its effectiveness and the demerit in this study that it only used one test radial distribution system and the voltage profile was not optimally improved when compared to other optimization techniques applied to the same test feeder as in.

Taher, et al., [9] presents a biological inspired algorithm called Immune Algorithm which is used to optimally allocate the DSTATCOM in the radial distribution feeder. The proposed technique is tested on two test systems IEEE 33 bus and IEEE 69 bus. The results were promising but in the case of testing IEEE 33 bus radial distribution feeder when compared to the results obtained using the harmony search algorithm technique in [8] are better regarding the total power loss reduction of the RDS and the total annual costs.

Guptaa, et al., [10] uses sensitive method to determine the best locations for placing the DSTATCOM in the tested IEEE 33 bus radial distribution feeder. After selecting one of the two sensitive methods proposed in this study, the variational technique is used in order to select the proper size of the DSTATCOM. The disadvantage in this work that it only tested the technique on single RDS and also regarding the tested IEEE 33 bus RDS total annual energy saving obtained by other methods as in [9] is better than the one reached in this work.

Yuvaraj, et al., [11] introduces the bat algoritm which is used to find the optimal size of DSTATCOM to be placed in RDS and the placement of the sized DSTATCOM is decided by voltage stability index method. To valiade the proposed technique for optimal location and sizing of DSTATCOM. It is tested using two test systems IEEE 33 bus and IEEE 69 bus radial distribution systems. The obtained results for the tested IEEE 33 bus RDS show that the size of the installed DSTATCOM is larger than the size used by other optimization methods applied to the same test feeder. Shah, et al., [12] presents the effect of optimal placement of STATCOM for voltage stability purposes by using load sensitivity factors. By varying the loads on each load bus, the effect of STATCOM is realized. The implementation is done on two test RDS systems IEEE 5 bus and IEEE 14 bus. But the status of active and reactive power losses is not presented and also the implementation should have included larger test feeders.

In this paper, the improved grey wolf optimization algorithm is applied to two different IEEE radial distribution feeders. This proposed technique is intended to find the optimal solutions to allocate and size DSTATCOM in any RDS. The algorithm follows a set of predetermined steps to find the global optimal solution for those kind optimization problems. The novelity factor in this study that the proposed technique is used for the first time to find a solution for this kind of optimization problems which includes determining the optimal location and size of DSTATCOM in any radial distribution feeder. This new algorithm could find the optimal solution regarding the lowest system minimum power losses accompanied by voltage profile improvement within the predefined optimiztion problem limits such as power balance constraints, bus voltage constraints and reactive power compenstation constraints. The rest of the paper is divided as follows: Section 2 (Research method) introduces the grey wolf optimization algorithm and its modifications. Also, the algorithm steps taken to approach and solve the problem of optimal placement of DTATCOM in RDS are explained. Section 3 (Results and Analysis) introduces the implementation and simulation results applied to two test systems. Also, comparison of the results to other optimization techniques applied to the same test feeders. Finally, Section 4 includes the conclusions of this study.

\section{RESEARCH METHOD}

\subsection{Grey wolf optimization algorithm (GWOA)}

GWOA is nature inspired algorithm that mimcs the behavior of the real grey wolves in nature by applying their techniques in searching, leadership and hunting the preys. The algorithm was introduced for the first time in [13]. From the study in [13-17]. Grey wolves are predators, in other words they are at the peak of the food chain. It is recorded that they live in a group. In most cases the group contains 5-12 individuals. GWO technique is a meta-heuristic algorithm which belongs to the swarm intelligence family. In the hunting process grey wolves divide themselves into packs. Figure 1 classifies them according to domination and power. There are four categories of grey wolves. The first one is leaders, which are called alpha (a) wolves and they are the most powerful and lead the whole pack in feeding, migration and hunting. The second levels are the beta (b) wolves; they help the leaders in decision making and replace the alpha 
wolves in case of death or illness. The least types of grey wolves are delta (d) and omega (x) wolves. Interestingly, the alpha is not necessarily the strongest member of the pack but thebest in terms of managing the pack. Gery wolves during the hunting process follow a set of well-known procedures: chasing, encircling, harassing and attacking. This makes them hunt large preys. GWO algorithm applies the same mechanism in nature, where it follows the pack hierarchy for organizing the different functions in the wolves' pack. Also, as in nature in the hunting process each wolf performs its role where the GWO pack's members are divided into four groups based on the category of the wolf's function. The four groups are alpha, beta, delta and omega, where the Alpha represents the best candidate solution found for hunting so far. Consequently, beta and delta represent the second and third best candidate solutions where omega is the least probable solution to the problem.

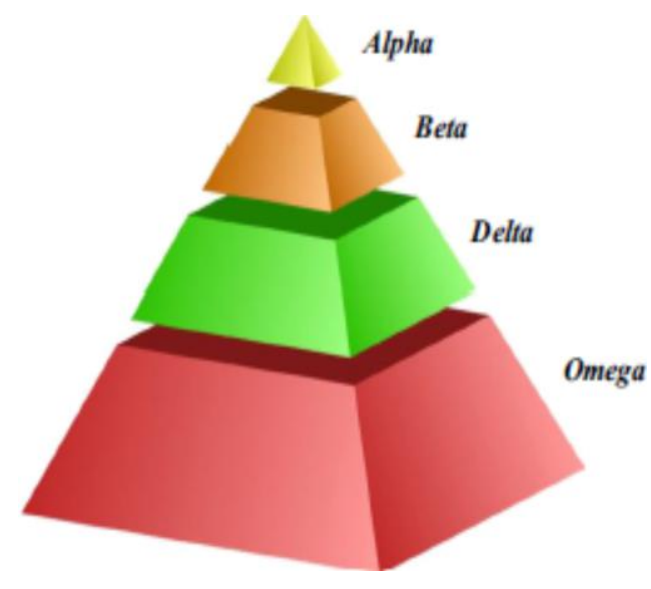

Figure 1. Grey wolves' social hierarchy

\subsubsection{Mathematical modeling}

\subsubsection{Encircling prey}

In order to mathematically model encircling behavior of the grey wolves the following equations are presented in [13-14]:

$$
\begin{aligned}
& \vec{D}=\left|\vec{C} \cdot \overrightarrow{X_{p}}(t)-\vec{X}(t)\right| \\
& \vec{X}(t+1)=\overrightarrow{X_{p}}(t)-\vec{A} \cdot \vec{D}
\end{aligned}
$$

where:

$\mathrm{t}$ indicates the current iteration,

$\vec{A}$ and $\vec{C}$ are coefficient vectors,

$\overrightarrow{X_{p}}(t)$ is the position vector of the prey,

$\vec{X}(t)$ indicates the position vector of a grey wolf.

The vectors $\vec{A}$ and $\vec{C}$ are calculated as follows:

$$
\begin{aligned}
& \vec{A}=2 \vec{a} \cdot \overrightarrow{r_{1}}-\vec{a} \\
& \vec{C}=2 \cdot \overrightarrow{r_{2}}
\end{aligned}
$$

where:

components of $\vec{a}$ are linearly decreased from 2 to 0 over the course of iterations $\overrightarrow{r_{1}}$ and $\overrightarrow{r_{2}}$ are random vectors in the range of $[0,1]$. From the above equations, a grey wolf in the position of $(X, Y)$ in the search space can update its position according to the position of the prey $\left(\mathrm{X}^{*}, \mathrm{Y}^{*}\right)$ different locations around the best agent can be reached with respect to the current position by varying the values of the vectors $\vec{A}$ and $\vec{C}$. So, a grey wolf can update its position inside the space around the prey in any random place by using the above mentioned equations. 


\subsubsection{Hunting}

During the hunting process, Grey wolves have the capability to find the prey and encircle them. The leader of the hunting is the alpha wolf. The beta and delta wolves may also contribute in the hunting process occasionally. However, in an abstract search space there is no clue about the location of the optimum prey. In order to model mathematically the hunting behavior of grey wolves, suggest that the alpha (best candidate solution) beta and delta have better knowledge about the potential location of prey. Therefore, store the first three best solutions found so far and force all the other search agents to change their positions according to the position of the best search agent. The following formulas and equations are presented in this regard to represent the previous explained behavior:

$$
\begin{aligned}
& \overrightarrow{D_{\alpha}}=\overrightarrow{C_{1}} \cdot \overrightarrow{X_{\alpha}}-\vec{X} \\
& \overrightarrow{D_{\beta}}=\overrightarrow{C_{2}} \cdot \overrightarrow{X_{\beta}}-\vec{X} \\
& \overrightarrow{D_{\delta}}=\overrightarrow{C_{3}} \cdot \overrightarrow{X_{\delta}}-\vec{X} \\
& \overrightarrow{X_{1}}=\overrightarrow{X_{\alpha}}-\overrightarrow{A_{1}} \cdot\left(\overrightarrow{D_{\alpha}}\right) \\
& \overrightarrow{X_{2}}=\overrightarrow{X_{\beta}}-\overrightarrow{A_{2}} \cdot\left(\overrightarrow{D_{\beta}}\right) \\
& \overrightarrow{X_{3}}=\overrightarrow{X_{\delta}}-\overrightarrow{A_{3}} \cdot\left(\overrightarrow{D_{\delta}}\right) \\
& \left.\overrightarrow{X_{\mathrm{X}}} \mathrm{t}+1\right)=\frac{\overrightarrow{X_{1}}+\overrightarrow{X_{2}}+\overrightarrow{X_{3}}}{3}
\end{aligned}
$$

In search space using these equations, a search agent changes and updates its position according to alpha, beta and delta. Also, the final position reached would be in a random place within a circle which is defined by the positions of alpha, beta, and delta. In short words, alpha, beta and delta determine the position of the prey and all other wolves update and change their positions in a random way around the prey.

\subsubsection{Exploration and exploitation in GWO}

In [15] during the optimization process, the algorithm performs two opposite actions which are exploration and exploitation. During the exploration phase, the algorithm tries to explore all the new areas of the problem search space by making changes in the solutions since the main purpose is to know the best areas of the search landscape and prohibit solutions from being trapped in a local optimum. While during exploitation phase, the main target is to enhance the calculated solutions obtained in the exploration process by knowing the neighbourhood parts of each solution. Therefore, updates in the solutions found should be made to converge towards the global optimal solution of the problem.

In GWO, searching for prey represents exploration phase and mathematically the (C) vector, (A) and (a) also represents it. The (C) vector presents the effect of obstacles to approaching prey in nature. In general, the wolves face obstacles during the hunting process which slows them and makes it harder when approaching the prey. In Summary, the searching process starts by intializing a random population of grey wolves) in the GWO algorithm. Over the course of iterations, alpha, beta, and delta wolves determine the exact position of the prey. each agent updates and changes its distance from the prey. The parameter (a) is decreased from 2 to 0 in order to assure exploration and exploitation, respectively. Agents tend to diverge away from the prey when $\mid \overrightarrow{|A|}>1$ and converge towards the prey when $\vec{A}<1$. Finally, the GWO algorithm is terminated by the satisfaction of an end condition.

\subsection{Modified grey wolf optimization algorithm (MGWOA)}

In order to improve the exploration phase in GWO, the value of $(\vec{a})$ is varied using an exponential function instead of changing it linearly as prposed in [18]. In this case the following equation is used:

$$
\mathrm{a}=2\left(1-\frac{\text { iter }^{2}}{\max i t e r^{2}}\right)
$$

where, iter is the current iteration, and max iter is the maxium number of iterations. 


\subsection{DSTATCOM structure}

DSTATCOM is a type of the flexiable AC transmissions (FACTs) devices, and it absorbs or supplies both the reactive and the active current at a point of common coupling (PCC). Actually, it is considerd a DC/AC converter, where it consists of a dc energy storage bank or a dc-link capacitor. The main role of the energy bank is supplying a constant DC voltage, which is converted to a 3-phase voltage. The AC output voltage feeds a coupling transformer that is commoned coupling with the RDS [19]. Mainly, the DSTATCOM operates as a variable synchronous voltage source, where both voltage magnitude and angles are tuned in order to control the bus voltage and improve the power factor. The connection of the DSTATCOM to the distribution system bus is illustrated as in Figure 2. Most properly, PID controller has been applied in many studies to control the state of this device; inject or absorb the electrical current. The bus voltage is regulated by DSTATCOM in the normal or abnormal conditions, where it injects the proper power to the bus. The power exchange might be for the active or reactive power, but in this paper the DSTATCOM is only for the reactive power exchange. Newton-Raphosn load flow calculation method has been applied in this work, and it is assumed that the distribution network is in balance conditions. A section of a sample distribution network is shown in Figure 3.

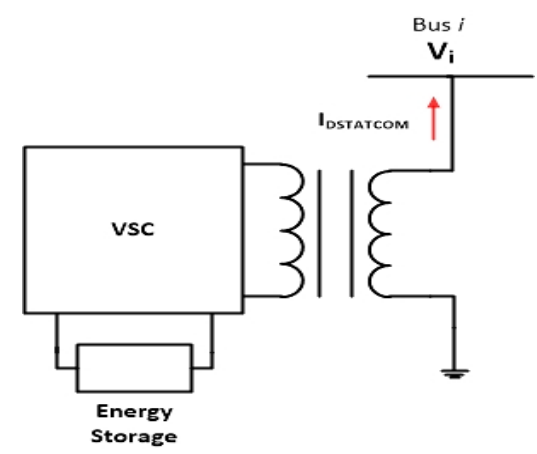

Figure 2. DSTATCOM connected to bus i

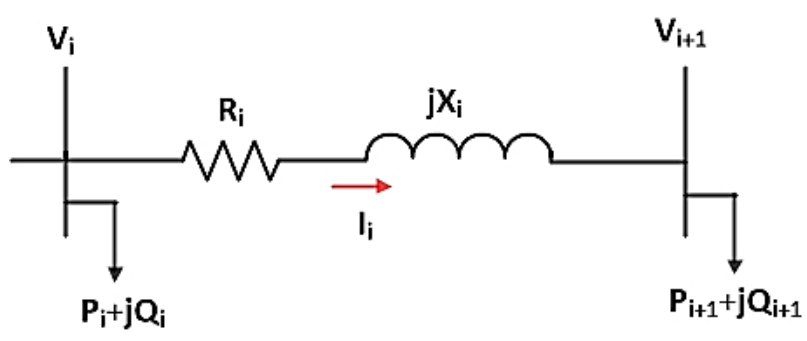

Figure 3. Single line diagram of two consecutive buses of a distribution system

In this Figure $3, R_{i}+j X_{i}$ is the impedance between the $i^{\text {th }}$ and $i+1^{\text {th }}$ buses. $V_{i}, P_{i}$, and $Q_{i}$ are voltage, active power, and reactive power of the $i^{\text {th }}$ bus respectively, and the same for the $i+1^{\text {th }}$ bus. Figure 4 illustrates the phasor diagram of Figure 3, and if KVL is applying the phasor equation is result as in (13):

$$
V_{i+1} \angle \theta_{i+1}=V_{i} \angle \theta_{i}-\left(R_{i}+j X_{i}\right) . I_{i} \angle \delta
$$

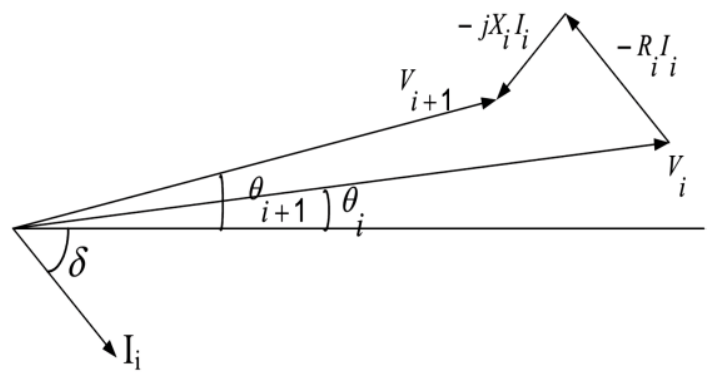

Figure 4. Phasor diagram of voltage and current of the system

here, $I_{i}$ is the flowing current from $i^{\text {th }}$ to $i+1^{\text {th }}$ buses. In this work, a DSTATCOM has been installed to improve the voltage of the $i+1^{t h}$ bus to reach the optimized level, as in Figure 5. Finally, this device is applied for regulating the bus voltage, reducing the system loss in steady state condition. It would be achievable if the current angle $\theta_{\text {DSTATCOM }}$ of the DSTATCOM is in the desired quadrature with respect to the voltage angle.

$$
\theta_{\text {DSTATCOM }}=\frac{\pi}{2}+\theta_{i+1}
$$


So, (13) is modified to the following:

$$
V_{i+1} \angle \theta_{i+1}=V_{i} \angle \theta_{i}-\left(R_{i}+j X_{i}\right) .\left(I_{i} \angle \delta+I_{\text {DSTATCOM }} \angle \theta_{\text {DSTATCOM }}\right)
$$

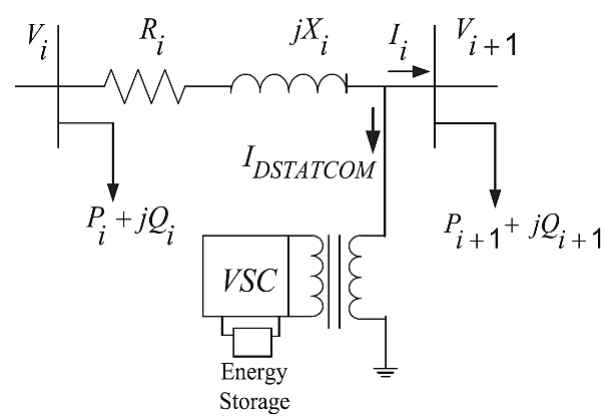

Figure 5. DSTATCOM installation at the $i+1^{\text {th }}$ bus

Figure 4 is modified according to (15), and the final phasor diagram is represented as in Figure 6. The DSTATCOM current angle is determined as in (14) and the current magnitude could be obtained from (16):

$$
\left|I_{\text {DSTATCOM }}\right|=\frac{V_{i+1} \cos \theta_{i+1}-a_{1}}{-a_{4} \sin \theta_{i+1}-a_{3} \cos \theta_{i+1}}
$$

where, $a_{1}$ and $a_{2}$ are the real and the imaginary of (13) respectively. while, $a_{3}$ is $-X_{i}$ and $a_{4}$ is $-R_{i}$. Finally, the injected reactive power $Q_{D S T A T C O M}$ is the multiplication of $V_{i+1}$ by $I_{D S T A T C O M}$ as in (17):

$$
j Q_{\text {DSTATCOM }}=V_{i+1} \angle \theta_{i+1} \cdot I_{\text {DSTATCOM }} \angle \theta_{\text {DSTATCOM }}
$$

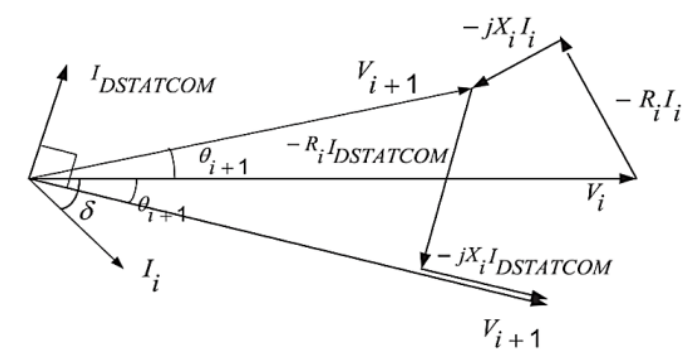

Figure 6. The final phasor diagram of voltage and current of system after installing the DSTATCOM

\subsection{Objective Function}

From [9] a multi-objective function is represented as in (18), to ensure that the DSTACOM is located in the optimal bus, and it contains two objective functions. The first objective is to minimize the system power loss as in (19). Additionally, in (20) demonstrates the second objective which is minimizing the cost of the DSTATCOM:

$$
\begin{aligned}
& O . F=\min \left\{\begin{array}{l}
O . F_{1} \\
O . F_{2}
\end{array}\right. \\
& O \cdot F_{1}=R D S_{\text {loss }} \\
& O \cdot F_{2}=T A C_{\text {Dstatcom }, i}
\end{aligned}
$$

The power loss minimization which is the first objective function is described in (21) as:

$$
P_{\text {loss }_{i}}=\sum_{i=1}^{N_{b}} R_{i} \cdot\left|I_{i}\right|^{2}
$$


where, $N_{b}$ is number of the system branches, $R_{i}$ is the branch resistance, and $I_{i}$ is the brach current. In (22) shows the second objective which is minimizing the cost due to power loss.

$$
T A C_{\text {Dstatcom }, i}=K_{e} \cdot \mathrm{Q}_{\text {DSTATCOM }} \cdot \mathrm{t}
$$

where:

$T A C_{\text {Dstatcom } i}$ is the total power loss cost

$K_{e}$ is the energy costof losses in $(\$ / \mathrm{Kwh})$

QDSTATCOM is the DSTATCOM size in KVAr

$\mathrm{t}$ is the load duration

The weighted-sum method has been applied to convert the multi-objective to single objective function where $w_{1}$ and $w_{2}$ are weight factors and (18) is rewritten as follows:

$$
O . F=w_{1} \cdot \sum_{i=1}^{N_{b}} R_{i} \cdot\left|I_{i}\right|^{2}+w_{2} \cdot\left(T_{A} C_{\text {Dstatcom }, i}\right)
$$

Finally, the main constraints of the proposed objective function are described in both (24) and (25), where in (24) the voltage constraints are defined. The upper and lower limits of the DSTATCOM reactive power capacity are demonstrated in (25).

$$
V_{\min } \leq V_{i} \leq V_{\max }
$$

Where, $V_{\min }$ and $V_{\max }$ are the minimum and maxiumim limits respectively of the bus voltage. While, in (25) $\mathrm{Q}_{\mathrm{STATCOM}}^{\min }$ and $\mathrm{Q}_{\mathrm{STATCOM}}^{\max }$ are the minimum and maximum limits respectively of the DSTATCOM unit size in $\mathrm{kVAr}$.

$$
\mathrm{Q}_{\mathrm{STATCOM}}^{\min } \leq Q_{\text {STATCOM }} \leq \mathrm{Q}_{\mathrm{STATCOM}}^{\max }
$$

\subsection{Algorithm steps}

- $\quad$ Using Newton Rapshon method solve the load flow problem for the given test feeder and determine the system total power loss and system voltage profile.

- Initialize the random number of search agents, set the iteration counter=1, set max number of iterations, set the problem predefined constraints for DSTATCOM size, bus voltage limit and maximum current in line.

- $\quad$ Read the system parameters which include the system real power loss, line data, system constraints and bus data for generated population by performing load flow calculations.

- Intialize the population $\mathrm{X}$ randomly, where each agent represents a candidate solution.

$$
X_{m}=X_{m}^{\min }+\operatorname{rand}(0,1)\left(X_{m}^{\max }-X_{m}^{\min }\right)
$$

where $\mathrm{m}=1,2,3, \ldots, \mathrm{N}$.

- Calculate the fitness function for all population using load flow calculations and taking constraints into account.

- Determine and update $\mathrm{X}_{\alpha}, \mathrm{X}_{\beta}, \mathrm{X}_{\delta}$ where $\mathrm{X}_{\alpha}$ is the first best search agent, $\mathrm{X}_{\beta}$ is the second-best search agent, $X_{\delta}$ is the third best search agent

- $\quad$ Update and move the rest of search agents usings equations (1-12).

- Claculate the objective function for the updated agents.

- $\quad$ Update the values of A, C, an according to (3-4) \& (12).

- $\quad$ Repeat until the maximum number of iterations is performed and print the results.

\section{RESULTS AND ANALYSIS}

\subsection{The First Feeder}

The first tested feeder using the proposed modified grey wolf optimization algorithm MGWOA is the 33-bus system. The system single line diagram is shown in Figure 7. This test feeder has a total load of $3720 \mathrm{~kW}$ and $2300 \mathrm{kVAr}$ at a voltage level of $12.66 \mathrm{kV}$. The system data are found in [20-23]. The configuration of the system before installing DSTATCOM is as follow: the real power loss in $\mathrm{kW}$ is 210.9 and the minimum bus voltage is 0.9038 . The results of the system performance before and after 
connecting the DSTATCOM to the test feeder are shown in Table 1. Also Table 1 presents the results obtained by the proposed technique and other recent optimization methods applied to same test feeder. It is concluded from the results that the proposed method performs superior process regarding the most minimized system power losses and the best improved voltage profile compared to other optimization techniques as bat algorithm and immune optimization algorithm. The reduction in system active power losses has reached $29.15 \%$ and minimization of system reactive power losses has achieved $29 \%$ accompanied by reduction in cost due to power loss. Also, the minmum bus voltage in p.u. is raised from 0.91 to 0.93. Figure 8 shows the effectiveness of the proposed method after placing the DSTATCOM in reducing total system active power losses compared to recent optimization techniques as BAT algorithm. From the obtained results shown in Table 1 and Figure 8 for the 33 bus test feeder, the novelity factors in the results were the most minimized total real power losses in the test feeder, the most improved voltage profile for the test feeder and the most reduction in costs due to total power loss in test system which showed the effectiveness of applied method.

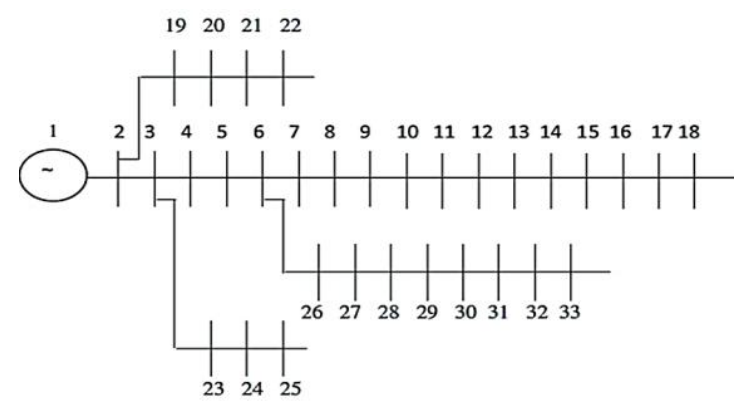

Figure 7. Single line diagram of IEEE 33 bus system

Table 1. Optimal results of 33-bus feeder after single DSTATCOM placement

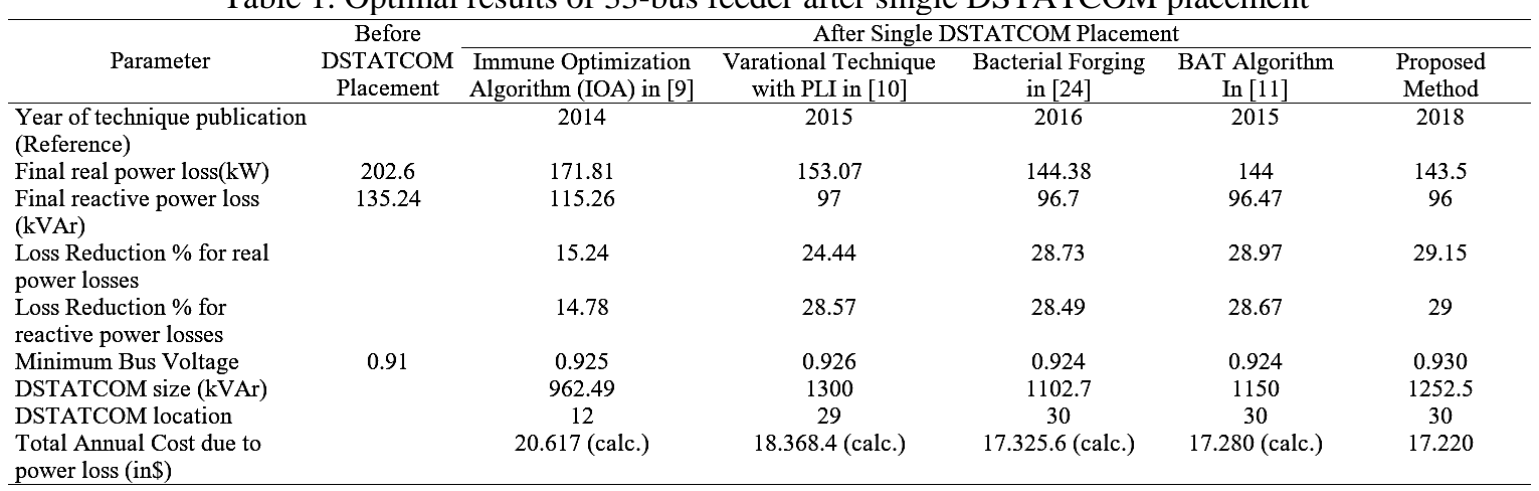

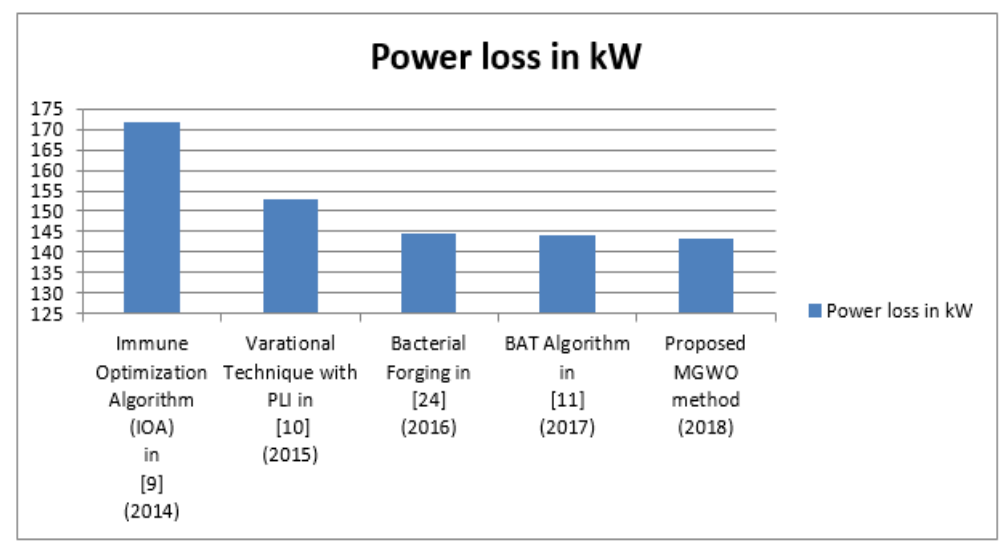

Figure 8. Comparsion of the active power losses reductions in the IEEE 33 bus test system after placing DSTATCOM using different optimization algoritms 


\subsection{The second feeder}

As in Figure 9, the second tested radial distribution feeder is a larger scale system with 69 buses and 68 branches. The line and bus data of this system are taken from [20-23]. The base values are 100MVA and $12.66 \mathrm{KV}$ and the total real and reactive power loads of the system are 3.80MWand 2.69MVAr, respectively. Table 2 represents a comparison between four different recent techniques applied to the tested feeder, it is noted that the proposed method has achieved the most reduction in real power loss in $\mathrm{Kw}$ and in $\mathrm{kVAr}$ and the most improved system voltage profile as the minimum bus voltage in the system has increased from 0.909 to $0.939 \mathrm{pu}$. Figure 10 shows the total active power loss in the system after connecting the DSTATCOM to the network using the proposed optimization technique and various recent optimization techniques. From the obtained results for the 69 bus test feeder, the novelity factors in the results were the most minimized total real power losses in the test feeder, the most improved voltage profile for the test feeder and the most reduction in costs due to total power loss in test system which confirmed the superiority of the applied technique

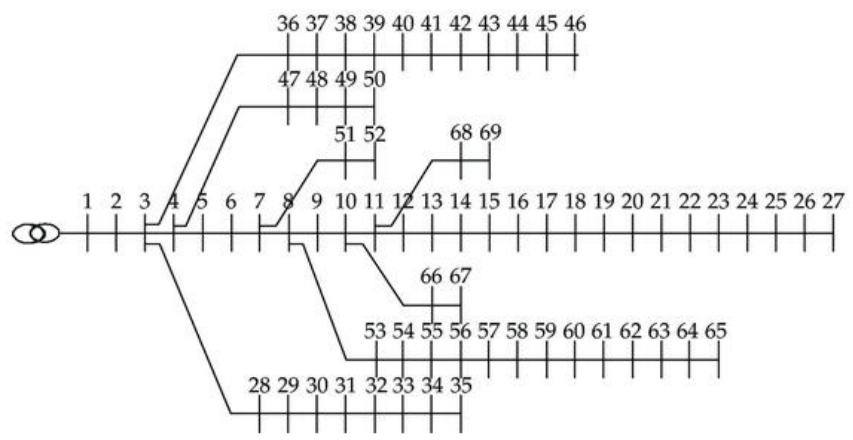

Figure 9. Single line diagram of IEEE 69 bus system

Table 2. Optimal results of 69-bus feeder after single DSTATCOM placement

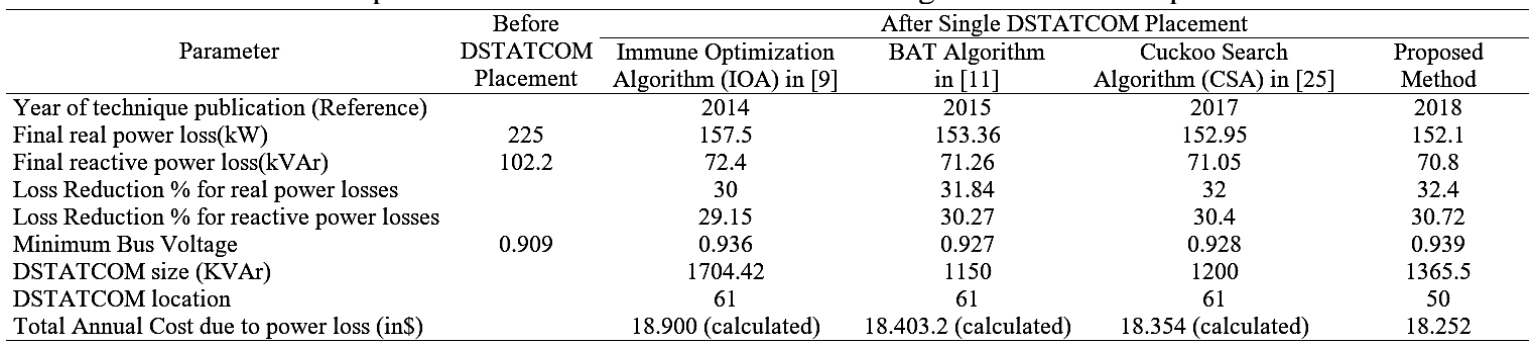

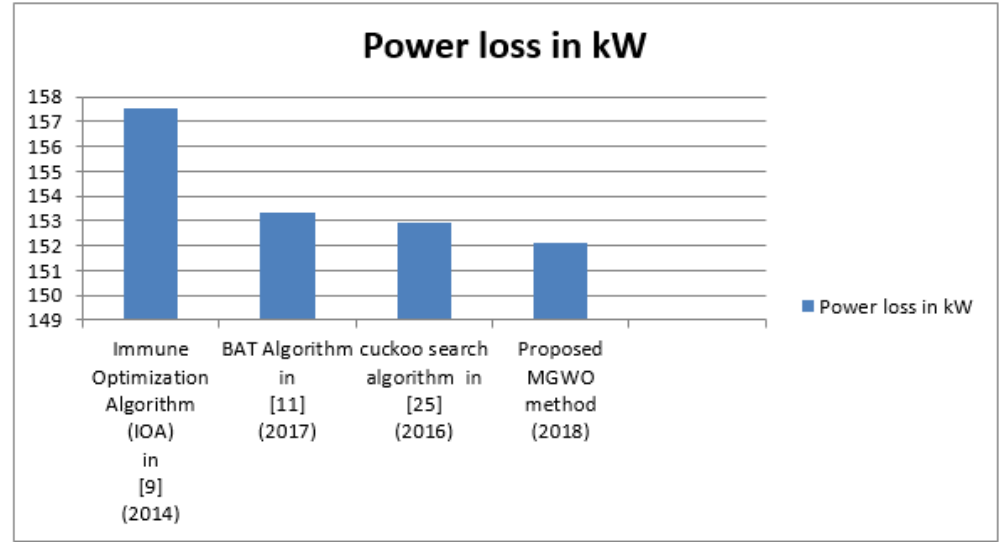

Figure 10. Comparsion of the active power losses reductions in the IEEE 69 bus test system after placing DSTATCOM using different optimization algoritms 


\section{CONCLUSION}

In this study, a modified grey wolf optimization algorithm is used to solve the problem of optimal allocation and sizing of DSTATCOM in radial distribution feeder. The proposed method is tested on different radial test feeders to ensure its effectiveness and superiority. The results have been compared with other optimization techniques such as bat algorithm and cuccko search algorithm. It is observed from the obtained results that the proposed technique has a superior performance regarding minimizing overall system real power losses, improving system voltage profile and reducing costs due to power loss.

\section{REFERENCES}

[1] R. H. Shehata, S. F. Mekhamer, A. Y. Abdelaziz, M. A. L. Badr, "Solution of the capacitor allocation problem using an improved whale optimization algorithm," International Journal of Engineering, Science and Technology, Vol. 10, pp. 1-11, 2018.

[2] S. Surender Reddy, "Optimal Placement of FACTS Controllers for Congestion Management in the Deregulated Power System," International Journal of Electrical and Computer Engineering (IJECE), Vol. 8, No. 3, pp. 1336-1344, 2018.

[3] Aziz Oukennou, Abdelhalim Sandali, and Samira Elmoumen, "Coordinated Placement and Setting of FACTS in Electrical Network based on Kalai-smorodinsky Bargaining Solution and Voltage Deviation Index," International Journal of Electrical and Computer Engineering (IJECE), Vol. 8, No. 6, pp. 4079-4088, 2018.

[4] Sekhane Hocine and Labed Djamel, "Optimal number and location of UPFC devices to enhance voltage profile and minimizing losses in electrical power systems," International Journal of Electrical and Computer Engineering (IJECE), Vol. 9, No. 5, pp. 3981-3992, 2019.

[5] Surekha Manoj, Puttaswamy P. S, "Importance of FACTS Controllers in Power Systems," International Journal of Advanced Engineering Technology, Vol. 2, No. 3, pp.207-212, 2011.

[6] Z. Yang, C Shen, M. L. Crow and L. Zhang, "An Improved STATCOM Model for Power Flow Analysis," 2000 Power Engineering Society Summer Meeting (Cat. No.00CH37134), 2000.

[7] Naseer M. Yasin and Haider A. Talib, "Genetic Based Optimal Location of STATCOM Compensator," International Journal of Applied Engineering Research, Vol. 13, No. 10, pp. 7516-7521, 2018.

[8] T. Yuvaraja, K. R. Devabalajia and K. Ravia, "Optimal placement and sizing of DSTATCOM using Harmony Search algorithm,” Energy Procedia, vol.79, pp.759 - 765, 2015.

[9] Seyed Abbas Taher, Seyed Ahmadreza Afsari, "Optimal location and sizing of DSTATCOM in distribution systems by immune algorithm," International Journal of Electrical Power \& Energy Systems, vol. 60, pp. 34-44, 2014.

[10] Atma Ram Guptaa and Ashwani Kumarb, "Energy savings using D-STATCOM placement in radial distribution System," Procedia Computer Science, vol.70, pp. 558-564, 2015.

[11] T. Yuvaraj, K. Ravi and K. R. Devabalaji, "DSTATCOM allocation in distribution networks considering load variations using bat algorithm," Ain Shams Engineering Journal, 2015.

[12] Abu Hachan Shah and Satyajit Bhuyan, "Variable Evaluation and Optimal Placement of STATCOM in Test Bus Systems," ADBU-Journal of Engineering Technology, Vol. 7, No. 1, pp.1-6, 2018.

[13] Seyedali Mirjalili, Seyed Mohammad Mirjalili and Andrew Lewis, "Grey Wolf Optimizer," Advances in Engineering Software, vol. 69, pp. 46-61, 2014.

[14] Hossam Faris, Ibrahim Aljarah, Mohammed Azmi Al-Betar, Seyedali Mirjalili, "Grey wolf optimizer: a review of recent variants and applications," Neural Computing and Applications, vol. 30, pp.413-435, 2018.

[15] Crepinsek M and Liu S-H, Mernik M, "Exploration and exploitation in evolutionary algorithms: a survey," ACM Computing Surveys (CSUR), vol.45, No. 3, pp. 35:1-35:33, 2013.

[16] M. A. Algabalawy, A.Y. Abdelaziz, S. F. Mekhamer, M.A.L. Badr ," Optimal Multi-Criteria Design of a New Hybrid Power Generation System Using Ant Lion and Grey Wolf Optimizers," Eighteenth international middle east power systems conference (MEPCON), Cairo , pp.138-146,2016.

[17] D. P. Ladumor, I. N. Triveedi, R. H. Bhesdadiya and P. Jangir , "optimal power flow problems solution with STATCOM using meta-heuristic algorithm," Third International Conference On Advances In Electrical, Electronics, Information, Communication And Bio-Informatics (AEEICB), Chennai, pp. 392-396, 2017.

[18] Mittal N, Singh U and Sohi BS, "Modified grey wolf optimizer for global engineering optimization," Applied Computational Intelligence and Soft Computing, vol. 2016, pp. 1-16, 2016.

[19] Blazic B and Papic I., "A new mathematical model and control of DSTATCOM for operation under unbalanced conditions," Electrical Power System Research, vol. 72, no. 3, pp.279-287, 2004.

[20] Hingorani N.," Introducing custom power," IEEE Spectrum, vol. 32, no.6, pp. 41-48, 1995.

[21] Nilsson S., "Special application consideration for custom power systems," IEEE conference power engineering society, vol. 2, pp. 1127-1131, 1999.

[22] A. Adya, B. Singh, J. R. P. Gupta and A. P. Mittal, "Application of D-STATCOM for isolated systems," 2004 IEEE Region 10 Conference TENCON 2004, Chiang Mai, vol. 3, pp. 351-354, 2004.

[23] D. Rama Prabha and T. Jayabarathi, "Optimal placement and sizing of multiple distributed generating units in distribution networks by invasive weed optimization algorithm," Ain Shams Engineering Journal, vol. 7, no.2, pp. 683-694, 2016. 
[24] K. R. Devabalaji and K. Ravi, "Optimal size and siting of multiple DG and DSTATCOM in radial distribution system using Bacterial Foraging Optimization Algorithm," Ain Shams Engineering Journal, vol.7, no. 3, pp.959-971, 2016.

[25] T. Yuvaraj, K. Ravi and K. R. Devabalaji, "Optimal Allocation of DG and DSTATCOM in Radial Distribution System Using Cuckoo Search Optimization Algorithm," Hindawi Modelling and Simulation in Engineering, vol. 2017, pp.1-11, 2017.

\section{BIOGRAPHIES OF AUTHORS}

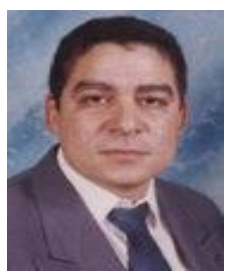

Dr. S. F. Mekhamer was born in Egypt in 1964. He received the B. Sc. and M.Sc. degrees in electrical engineering from Ain Shams University, Cairo, Egypt, and the Ph.D. degree in electrical engineering from Ain Shams University with joint supervision from Dalhousie University, Halifax, NS, Canada, in 2002. He is currently a Professor in the Department of Electric Power and Machines, Ain Shams University. His research interests include power system analysis, power system protection, and applications of AI in power systems. Currently, he is a professor in Future University in Egypt (FUE) on leave from Ain Shams University.

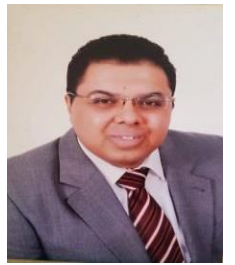

Eng. R. H. Shehata was born in Egypt in 1986.He received the B.Sc. and M.Sc. degrees in electrical engineering from Ain Shams University, Egypt, in 2008 and 2014, respectively and is currently registered as a Ph.D. researcher in electrical engineering in the same university. Since 2009, he has been working for the Arab Contractors in Egypt and currently occupies the position as a senior electrical power system design and tender engineer. Through this position, he has participated in many local, regional and African projects about the design and tender studies of different power systems in buildings and water stations with the different national and international organizations.

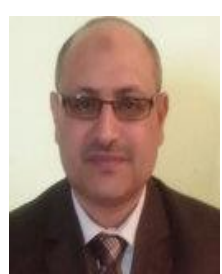

Dr. A. Y. Abdelaziz Received the B.Sc. and M.Sc. degrees in electrical engineering from Ain Shams University, Egypt, in 1985 and 1990, respectively, and the Ph.D. degree in electrical engineering according to the channel system between Ain Shams University, Egypt, and Brunel University, U.K., in 1996. He is currently a Professor of electrical power engineering at Ain Shams University. Dr. Abdelaziz is the chair of IEEE Education Society chapter in Egypt, senior editor of Ain Shams Engineering Journal, editor of Electric Power Components \& Systems Journal, editorial board member, associate editor and editorial advisory board member of several international journals and conferences. He is also a member in IET and the Egyptian Sub-Committees of IEC and CIGRE'. He has been awarded many prizes for distinct researches and for international publishing from Ain Shams University, Egypt. He has authored or coauthored more than 320 refereed journal and conference papers in his research areas which include the applications of artificial intelligence, evolutionary and heuristic optimization techniques to power system operation, planning, and control.

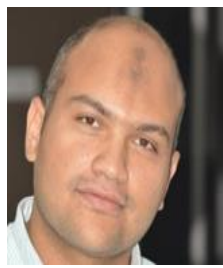

Dr. M. A. Al-Gabalawy, he was born in 1983, in Egypt. He had finished his B.Sc. degree in 2005 in honor from the electrical engineering department, Cairo University. In 2011 and 2017 he has been awarded the M.Sc. and $\mathrm{PhD}$ degrees respectively from the electrical engineering department, Ain Shams University. Currntly, the main research interest is in the field of the energy management and energy control applying new artifial intelligence algorithms. 